\title{
DIGITALCOMMONS
}

@WAYNESTATE —

Wayne State University

9-10-2013

\section{Feeling the heat? Substantial variation in temperatures does not affect the proportion of males born in Australia}

\author{
Barnaby J. Dixson \\ University of New South Wales, Sydney, Australia, b.dixson@unsw.edu.au \\ John Haywood \\ Victoria University of Wellington, New Zealand \\ Philip J. Lester \\ Victoria University of Wellington, New Zealand \\ Diane K. Ormsby \\ Victoria University of Wellington, New Zealand
}

\section{Recommended Citation}

Dixson, Barnaby J.; Haywood, John; Lester, Philip J.; and Ormsby, Diane K., "Feeling the heat? Substantial variation in temperatures does not affect the proportion of males born in Australia" (2013). Human Biology Open Access Pre-Prints. Paper 36.

http://digitalcommons.wayne.edu/humbiol_preprints/36 


\title{
Feeling the heat? Substantial variation in temperatures does not affect the proportion of males born in Australia
}

\author{
Barnaby J. Dixson ${ }^{\mathrm{a}, *}$, John Haywood ${ }^{\mathrm{b}}$, Philip J. Lester ${ }^{\mathrm{c}}$, Diane K. Ormsby ${ }^{\mathrm{c}}$ \\ ${ }^{a}$ Evolution \& Ecology Research Centre, School of Biological, Earth \& Environmental Sciences, \\ University of New South Wales, Kensington, Sydney. \\ ${ }^{\mathrm{b}}$ School of Mathematics, Statistics and Operations Research, Victoria University of Wellington, \\ Wellington, New Zealand. \\ ${ }^{\mathrm{c}}$ School of Biological Sciences, Victoria University of Wellington, Wellington, New Zealand.
}

* Correspondence address. Tel: +61-2-9385-8068; E-mail: b.dixson@unsw.edu.au

Keywords: ambient temperature, tropical climate, secondary sex ratio, stress, time series.

Running title: The Australian secondary sex ratio 


\begin{abstract}
The global proportion of male births has been shown to vary with climate, with a higher proportion of male births documented in colder climates. Here we examined the hypothesis that ambient temperature predicts fluctuations in the proportion of male births in Australia and within seven Australian states using historical annual data spanning 1910-2009. We predicted that within states with tropical ambient temperatures the proportion of male births would decrease when ambient temperatures are higher. Considering the national composite births for the whole of Australia first, the proportion of males born ranged only from 0.510 to 0.517 . We observed no relationship between the proportion of male births and the mean annual temperature in the concurrent or previous years for Australia as a whole. Secondly, the analyses for the seven Australian regions provided a total of 14 estimated relationships. We found there was no association between ambient temperature in the previous or concurrent year and the proportion of males born for all 14 comparisons. Thus, we found no evidence of a negative relationship between ambient temperatures in the concurrent or previous year and the proportion of males born in the tropical regions of Australia, and no evidence of any relationship in the more temperate Australian regions or in Australia as a whole.
\end{abstract}


While Fisher (1930) proposed a 1:1 sex ratio as optimal for the fitness of a species, evolutionary biologists studying animal sex ratios have noted that temporal fluctuations in biotic and abiotic factors can profoundly affect sex allocation (Trivers and Willard 1973). Contemporary human populations have a consistently male biased birth sex ratio (the secondary sex ratio: SSR), which is currently estimated at 107 boys born for every 100 girls globally (Central Intelligence Agency 2012). Natural selection may have favoured mechanisms in women that select in utero for the offspring that will be most reproductively successful in given environmental circumstances (Catalano 2011; James 2009, 2010; Navara 2010). Male foetuses appear to be more vulnerable to stressors (Catalano 2011), with political unrest, natural disasters (e.g. earthquakes) and layoffs from employment being just several in a long list of traits that are associated with lowering the male bias in SSRs (Catalano et al. 2010; James 2009, 2010; Navara 2010). In contrast, more favourable economic, political and nutritional circumstances are associated with an increase in the male bias in SSRs (Catalano et al. 2010; James 2010). More males were also born during the First and Second World Wars in Europe, which may be in response to greater mortality of young reproductively capable men (James 2009). It is argued that birth cohorts are more male biased within these circumstances as a male would have greater opportunity to augment their life-time reproductive success (Catalano 2011; Clutton-Brock and Isvaran 2007; Møller et al. 2009).

In mammals, temporal fluctuations in ambient temperature adversely influence reproductive performance in adults, as well as foetal and postnatal survivability (Coulson et al. 2001; Deutsch et al. 2008; Hamid et al. 2012). In humans oscillations in ambient temperature are also associated with greater mortality in adults (Basu and Samet 2002; Lerchl 1998; Young and Mäkinen 2010) and predict the survivability of new-borns, with both increases (Catalano et al. 2008) and decreases (Young and Mäkinen 2010) in ambient temperature during gestation being 
negatively associated with survival during the first year of childhood (Catalano et al. 2008, 2012; Young and Mäkinen 2010). These effects appear to be more pronounced for males than females and thus it is argued that climatic shifts cause gestational stress that affects sex allocation in humans (Catalano 2011; Catalano et al. 2008; Helle et al. 2008, 2009; Navara 2009). Indeed, variation in environmental factors such as climate, ambient temperature and rainfall appear to predict fluctuations in the human SSR, with more males being born within more favourable ecological conditions (Catalano et al. 2008; Helle et al. 2009). This pattern is in accord with evolutionary theory that fewer males will be born during stressful periods, as a weaker male would not survive to reproduce where a female might (Trivers and Willard 1973), and suggests a role for ambient temperature in sex allocation of human births (Catalano et al. 2008; Helle et al. 2008, 2009).

Interestingly, the SSR is significantly less male-biased at tropical latitudes than at temperate and subarctic latitudes (Navara 2009), which may be a mechanism for explaining the trend for lower SSRs among African populations and women of African descent (Garenne 2002). Time-series analyses conducted within subarctic climates of Finland and across Scandinavia using long-term historical datasets demonstrated that more males are born in years with relatively higher annual mean temperatures (Catalano et al. 2008; Helle et al. 2008, 2009). However, this finding does not extend to studies conducted within temperate climates in the Southern Hemisphere. Thus, within New Zealand the annual SSR remained consistently male biased from 1876-2009 with no relationship to fluctuations in ambient temperature (Dixson et al. 2011). Further, analyses of 30 years of monthly birth data revealed that the SSR in New Zealand was unrelated to seasonal patterns in ambient temperature (Dixson et al. 2011). Finally, no relationship was found between the proportion of male stillbirths and fluctuations in ambient 
temperature from 1929-2009 in New Zealand. In a follow-up study, which tested for geographic variability in the proportion of males born across the latitudinal gradients spanning the North and South Islands of New Zealand, there was no variability in the proportion of male births (Dixson et al. 2013).

These findings suggest that while more males may be born during warmer periods, this effect could be specific with regards to the patterns in climatic variation within the region being studied. Globally, the proportion of males born is greater in subarctic and temperate climates than in tropical climates (Navara 2009). There appears to be a positive relationship between ambient temperature and male births in subarctic climates (Catalano et al. 2008; Helle et al. 2008, 2009) and a neutral effect within temperate climates (Dixson et al. 2011, 2013). It may be that the conditions within tropical climates have the reverse effect on sex allocation, so that increases in ambient temperature induce maternal stress during gestation and result in a lowering of the proportion of male births (McLachlan and Storey 2003; Navara 2009). Here we test the hypothesis that ambient temperature is negatively related to the proportion of male births within a tropical environment using historical national and regional birth records and climate data from Australia. We hypothesized that those years that experienced peaks in ambient temperature within regions with tropical climates would be accompanied with, or followed by, a lowering of the proportions of males born.

\section{Materials and Methods}

The outcome variable in our analysis is the proportion of males born nationally and regionally within Australia over the last century. Australia is a continent comprised of seven states; the Northern Territory, Western Australia, Queensland, New South Wales (including the Australian 
Capital Territory), South Australia, Victoria and Tasmania (Figure 1). Historical data on the number of live male and female births were obtained for each of the seven territories of Australia, as well as a national composite, from the Australian Bureau of Statistics (http://www.abs.gov.au/). These data spanned 1910-2009, except for the Northern Territory where we did not use data prior to 1946 due to small sample sizes of recorded births (mean sample size of 82.6 births per year for 1910-1945, compared to 2360.2 for 1946-2009). There are no data available on births for the period of 1969-1973. Historical data for ambient temperature nationally and for each state were obtained from the Australian Government Bureau of Meteorology (http://www.bom.gov.au).

\section{FIGURE 1 ABOUT HERE}

We used transfer function (Autoregressive Integrated Moving Average, commonly known as ARIMA) models (Box et al. 2008) to estimate the dynamic effects of current and previous year temperature on the proportion of males born nationally and regionally, following the statistical analyses described by Catalano et al. (2008) and Dixson et al. (2011, 2013). In addition, in order to identify any unusual outlying observations or structural changes that are best modelled explicitly as functions of time, we used an intervention analysis approach (Box and Tiao 1975; Tsay 1986). The original assumptions of transfer function (ARIMA) models include equally spaced observation intervals, weak stationarity (i.e. constant mean and autocovariance functions, after suitable data transformation), and a minimum length of approximately 50 observations (Box et al. 2008). Models were tested to ensure a lack of residual autocorrelation using the Ljung-Box portmanteau statistic (Ljung and Box 1978), which indicated that all models discussed below had no residual structure $(p>0.05)$. Therefore the dynamic behaviour of the 
outcome variables was modelled appropriately in all our data. Computations used SPSS (SPSS 2009).

\section{Results}

The annual mean temperatures ranged from the Tasmanian minimum of $9.3^{\circ} \mathrm{C}$ in 1949 , to the Northern Territories maximum of $26.6^{\circ} \mathrm{C}$ in 2005 (Figures 2 and 3). This represents a maximum difference of $17.3^{\circ} \mathrm{C}$ between states. The variation in temperature between states was substantially greater than the intra-state variation. For example, the maximum annual mean temperature recorded in Tasmania was $11.4^{\circ} \mathrm{C}$ in 1988 (a maximum difference in annual mean temperature of $2.1^{\circ} \mathrm{C}$ within Tasmania).

Considering the national composite births for the whole of Australia first, the proportion of males born ranged only from 0.510 in 1924 to 0.517 in 1956 (Figure 2). Our transfer function model indicated that there was no influence of mean annual temperature in the concurrent or previous years on the proportion of male births, as all the confidence intervals for the parameter estimates included zero (Table 1).

\section{FIGURES 2 and 3 ABOUT HERE}

\section{TABLE 1 ABOUT HERE}

The analyses for the seven Australian regions provided a total of 14 estimated relationships between the proportion of males born and the concurrent or previous year's temperature (seven current year temperature series, and seven for the previous year). As displayed clearly in Figure 3, variation in the proportion of male births increases as population size decreases. The estimated effect sizes were all small (Table 1). Five of the estimates for the relationship in the current year were negative and two positive. Three of the previous year 
estimates were negative and four positive. Thus, from 14 estimates we have a near equal split of eight negative values and six positive ones. All the confidence intervals for these parameter estimates included zero, indicating no influence of mean annual temperature in the concurrent or previous years on the proportion of male births (Table 1).

\section{Discussion}

This study showed that from 1910-2009, concurrent and previous year annual mean ambient temperatures were unrelated to fluctuations in the proportion of male births in Australia. These findings differ from some previous studies in which time-series analyses were used to explore the relationship between the secondary sex ratio (SSR) and fluctuations in annual mean ambient temperature. For example, in Finland and elsewhere in Scandinavia more males are born in warmer years (Helle et al. 2008, 2009; Catalano et al. 2008). However, unlike in Scandinavia, fluctuations in annual mean ambient temperatures in New Zealand are unrelated to rates of male live births or stillbirths (Dixson et al. 2011). Likewise, in the current study, using a national composite of the proportion of male births and annual ambient temperature, we found no relationship between temperature and fluctuations in the male birth rates in Australia. Ambient temperature differs dramatically between Scandinavia, New Zealand and Australia. New Zealand's mean annual ambient temperature of $12.2^{\circ} \mathrm{C}$ over the period $1876-2009$ contrasts markedly with the mean annual temperature of $3.4^{\circ} \mathrm{C}$ observed in Scandinavia from 1865-1914 (Catalano et al. 2008). Further, Australia's mean annual ambient temperature of $21.7^{\circ} \mathrm{C}$ over the period 1910-2009 is substantially higher than is typically found in New Zealand and Scandinavia. Taken together, there appears to be a positive relationship between ambient 
temperatures and the proportion of male births nationally within subarctic climates, but no relationship within temperate or tropical climates.

In the present study we also investigated the relationship between ambient temperature and the proportion of male births within seven states in Australia. These states differ markedly in ambient temperature, with a maximum difference in annual mean temperatures of $17.3^{\circ} \mathrm{C}$. However, we found there was no association between ambient temperature in the previous or concurrent year and the proportion of males born in all cases. These results are similar to a regional analysis conducted within the North and South Islands of New Zealand that demonstrated no association between ambient temperatures and the proportion of male births (Dixson et al. 2013). It is possible that other factors besides ambient temperature are influencing variation in the proportion of males born in Australia and New Zealand. For example, maternal nutritional status and, in particular, preconception energy intake was positively associated with a greater proportion of male births in a UK study (Mathews et al. 2008). Further, in Helle et al.'s (2009) study where ambient temperature was positively associated with the SSR, periods of famine showed a negative association. Thus, future studies investigating factors beyond environmental temperatures will be necessary for explaining fluctuations in the Australian SSR. Interestingly, within African countries and among women of African descent, the SSR is less male biased compared with non-African women (Garenne 2002; Kaba 2008). In warmer climates in Europe a greater male bias in SSRs has been reported. However, this pattern was not found in North America (Grech et al. 2002). Once again, when taking the literature together, the association between regional ambient temperature and variation in the proportion of males born provides little support for hypotheses that (a) more males are born when temperature increases within temperate climates and (b) less males are born when temperature increases in hot 
climates. The only significant associations between SSR and ambient temperatures have been in subarctic environments (Catalano et al. 2008; Helle et al. 2008, 2009). Our analyses and those of some others have not incorporated such cold conditions (e.g., Dixson et al. 2011, 2013; Grech et al. 2000, 2002), thus we cannot rule out effects of extremely low ambient temperatures on SSR. However, a recent study by Bjerregaard et al. (2012) quantified the SSR of 27 Arctic communities using historical data. The primary aim of that study was to test for effects of environmental contaminants on the SSR, as previous studies have associated downward trends in the SSR among Inuits to endocrine-disrupted pollution through exposure to persistent organic pollutants (Bjerregaard et al. 2012). However, the geographic regions included in the study represent populations that live in regions with pronounced differences in ambient temperatures. Interestingly, the study reported little variation in an SSR of 1.05 over time and between regions despite considerable climatic variation. In fact, the SSR of present day indigenous Greenland Inuits is 1.043 compared to 1.048 from 1901-1930 (Bjerregaard et al. 2012). Thus, while extreme cold temperatures in the Arctic affect infant survival (Young and Mäkinen 2010), whether or not fluctuations in temperature influence the SSR remains to be determined.

In conclusion, we found no evidence of a negative relationship between ambient temperatures in the concurrent or previous year and the proportion of males born in the tropical regions of Australia, and no evidence of any relationship in the more temperate Australian regions or in Australia as a whole. Our findings suggest that temperature-dependent sex allocation in humans is not universal. 


\section{Literature Cited}

Basu, R., and J. M. Samet. 2002. Relation between elevated ambient temperature and mortality: A review of the epidemiologic evidence. Epidemiol. Rev. 24: 190-202.

Bjerregaard, P., S. Chatwood, B. Denning et al. 2012. Sex ratios in the arctic—do man-made chemicals matter? Am. J. Hum. Biol. 24: 165-169.

Box, G. E. P., G. M. Jenkins, and G. C. Reinsel. 2008. Time Series Analysis: Forecasting and Control, 4th edn. New Jersey: Wiley.

Box, G. E. P., and G. C. Tiao. 1975. Intervention analysis with applications to economic and environmental problems. J. Am. Stat. Assoc. 70: 70-79.

Catalano, R. T. 2011. Selection in utero contributes to male longevity deficit. Soc. Sci. Med. 72: 999-1003.

Catalano, R. T., T. Bruckner, and K. R. Smith. 2008. Ambient temperature predicts sex ratios and male longevity. Proc. Natl. Acad. Sci. USA 105: 2244-2247.

Catalano, R. T., T. Bruckner, K. R. Smith et al. 2012. Temperature oscillations may shorten male lifespan via natural selection in utero. Climatic Change 110: 697-707.

Catalano, R. T., C. E. M. Zilko, K. B. Saxton et al. 2010. Selection in utero: a biological response to mass layoffs. Am. J. Hum. Biol. 22: 396-400.

Central Intelligence Agency. 2012. https://www.cia.gov/library/publications/the-worldfactbook/fields/print_2018.html. Accessed 08/11/2012.

Clutton-Brock, T. H., and K. Isvaran. 2007. Sex differences in ageing in natural populations of vertebrates. Proc. R. Soc. B 274: 3097-3104.

Coulson, T., E. A. Catchpole, S. D. Albon et al. 2001. Age, sex, density, winter weather, and population crashes in Soay sheep. Science 292: 1528-1531. 
Deutsch, C. A., J. J. Tewksbury, R. B. Huey et al. 2008. Impacts of climate warming on terrestrial ectotherms across latitude. Proc. Natl. Acad. Sci. USA 105: 6668-6672.

Dixson, B. J., J. Haywood, P. J. Lester et al. 2011. Whatever the weather: Ambient temperature does not influence the proportion of males born in New Zealand. PLoS ONE 6(9):e25064.

Dixson, B. J., J. Haywood, P. J. Lester et al. 2013. Ambient temperature variation does not influence regional proportion of human male births in New Zealand. Journal of the Royal Society of New Zealand 43: 67-74.

Fisher, R. A. 1930. The Genetical Theory of Natural Selection. Oxford: Clarendon Press.

Garenne, M. 2002. Sex ratios at birth in African populations: A review of survey data. Hum. Biol. 74: 889-900.

Grech, V., P. Vassallo-Agius, and C. Savonna-Ventura. 2000. Declining male births with increasing geographical latitude in Europe. J. Epidemiol. Community Health 54: 244-246.

Grech, V., C. Savonna-Ventura, and P. Vassallo-Agius. 2002. Unexplained differences in sex ratios at birth in Europe and North America. Brit. Med. J. 324: 1010-1011.

Hamid, H.Y., M. Z.A.B. Zakaria, G. Y. Meng et al. 2012. Effects of elevated ambient temperature on reproductive outcomes and offspring growth depend on exposure time. The Scientific World Journal Article ID: 359134, doi: 10.1100/2012/359134.

Helle, S., S. Helama, and J. Jokela. 2008. Temperature-related birth sex ratio bias in historical Sami: Warm years bring more sons. Biol. Letters 4: 60-62.

Helle, S., S. Helama, and K. Lertola. 2009. Evolutionary ecology of human birth sex ratio under the compound influence of climate change, famine, economic crises and wars. J. Anim. Ecol. 78: 1226-1233. 
James, W. H. 2009. The variation of human sex ratio at birth during and after wars, and their potential explanations. J. Theor. Biol. 257: 116-123.

James, W. H. 2010. Behavioural and biological determinants of human sex ratio at birth. J. Biosoc. Sci. 42: 587-599.

Kaba, A. J. 2008. Sex ratio at birth and racial differences: Why do black women give birth to more females than non-black women? Afr. J. Reprod. Health 12: 139-150.

Lerchl, A. 1998. Changes in the seasonality of mortality in Germany from 1946 to 1995: The role of temperature. Int. J. Biometeorol. 42: 84-88.

Ljung, G. M., and G. E. P. Box. 1978. On a measure of lack of fit in time series models. Biometrika 65: 297-303.

Mathews, F., P. J. Johnson, and A. Neil. 2008. You are what your mother eats: evidence for maternal preconception diet influencing foetal sex in humans. Proc. R. Soc. B 275: 16611668 .

McLachlan, J. C., and H. Storey. 2003. Hot male: can sex in humans be modified by temperature? J. Theor. Biol. 222: 71-72.

Møller, A. P., C. R. Fincher, and R. Thornhill. 2009. Why men have shorter lives than women: effects of resource availability, infectious disease, and senescence. Am. J. Hum. Biol. 21: $357-364$.

Navara, K. J. 2009. Humans at tropical latitudes produce more females. Biol. Letters 5: 524-527.

Navara, K. J. 2010. Programming of offspring sex ratios by maternal stress in humans: assessment of physiological mechanisms using a comparative approach. J. Comp. Physiol. [B] 180: 785-796. 
SPSS. 2009. PASW Statistics, Release Version 18.0.0. SPSS Inc., Chicago, IL, http://www.spss.com.

Trivers, R. L., and D. E. Willard. 1973. Natural selection of parental ability to vary the sex ratio of offspring. Science 179: 90-92.

Tsay, R. S. 1986. Time series model specification in the presence of outliers. J. Am. Stat. Assoc. 81: 132-141.

Young, T. K., and T. M. Mäkinen. 2010. The health of Arctic populations: Does cold matter? Am. J. Hum. Biol. 22: 129-133. 
Table 1. Estimated model coefficients and $95 \%$ confidence interval limits from time series analysis using transfer function (ARIMA) models to estimate the dynamic effects of annual mean ambient temperature on the proportion of males born. In each region this analysis estimated the relationship between current or previous year mean ambient temperature (after removal of local trends for all temperature series) and a selected ARIMA model for the proportion of male births*.

\begin{tabular}{|c|c|c|c|c|c|c|}
\hline \multirow[t]{3}{*}{ Region } & \multicolumn{3}{|c|}{ Current Year Temperature } & \multicolumn{3}{|c|}{ Previous Year Temperature } \\
\hline & Estimate & Lower & Upper & Estimate & Lower & Upper \\
\hline & & $95 \% \mathrm{CI}$ & $95 \% \mathrm{CI}$ & & $95 \% \mathrm{CI}$ & $95 \% \mathrm{Cl}$ \\
\hline $\begin{array}{l}\text { ACT and New South } \\
\text { Wales }\end{array}$ & -0.000 & -0.001 & 0.001 & 0.000 & -0.001 & 0.001 \\
\hline Northern Territories ${ }^{\mathrm{a}}$ & -0.000 & -0.006 & 0.006 & 0.002 & -0.004 & 0.008 \\
\hline Queensland & 0.002 & 0.000 & 0.004 & 0.000 & -0.002 & 0.002 \\
\hline South Australia & 0.000 & -0.002 & 0.002 & -0.002 & -0.004 & 0.000 \\
\hline Tasmania & -0.003 & -0.007 & 0.001 & -0.002 & -0.006 & 0.002 \\
\hline Victoria & -0.001 & -0.003 & 0.001 & -0.000 & -0.002 & 0.002 \\
\hline Western Australia & -0.001 & -0.003 & 0.001 & 0.000 & -0.002 & 0.002 \\
\hline Whole of Australia & -0.000 & -0.001 & 0.001 & -0.000 & -0.001 & 0.001 \\
\hline
\end{tabular}

\footnotetext{
${ }^{a}$ Data only used from 1946 onwards, due to small numbers of births previously.

* All selected models had no residual autocorrelation, with Ljung-Box $P>0.05$ in all cases.
} 
Figure Captions:

\section{Figure 1. Map of Australian States}

A map showing the seven states in Australia. $n_{t}=$ total number of births in dataset; $n_{y}=$ average number of births per year.

\section{Figure 2. Annual proportion of male births and mean ambient temperature}

The mean proportion of male births and the annual mean ambient temperature in ${ }^{\circ} \mathrm{C}$ nationally and for the seven states in Australia. Error bars are one standard error of the mean.

Figure 3. Annual proportion of male births and mean ambient temperature for Australia, Queensland and Tasmania

The proportion of male births and the annual mean ambient temperature in ${ }^{\circ} \mathrm{C}$ nationally (A.), in Queensland (B.) and Tasmania (C.). $n_{t}=$ total number of births in dataset; $n_{y}=$ average number of births per year.

Figures are included on the following pages, but also supplied as separate, high quality JPG files. 
Figure 1

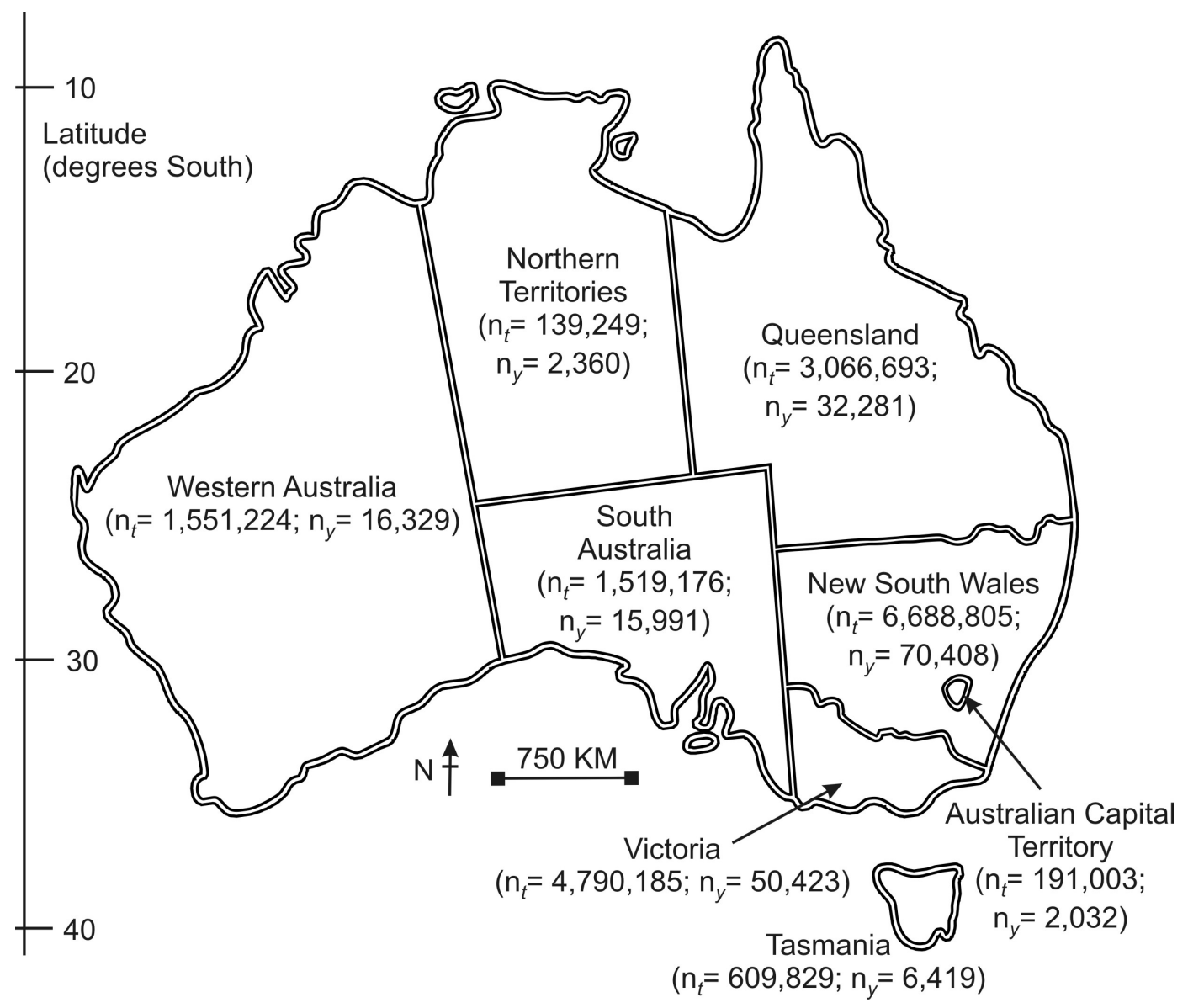


Figure 2

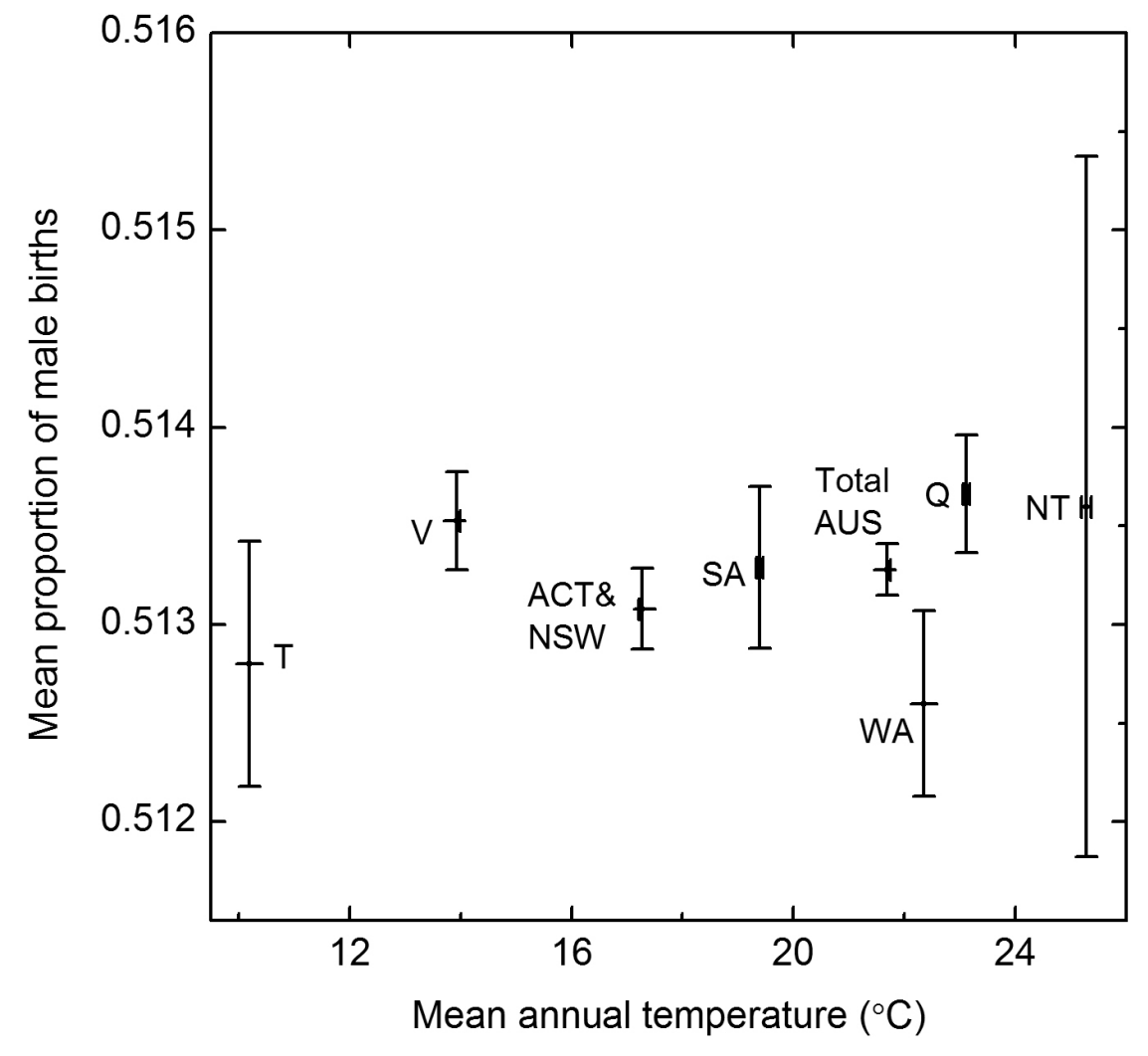


Figure 3
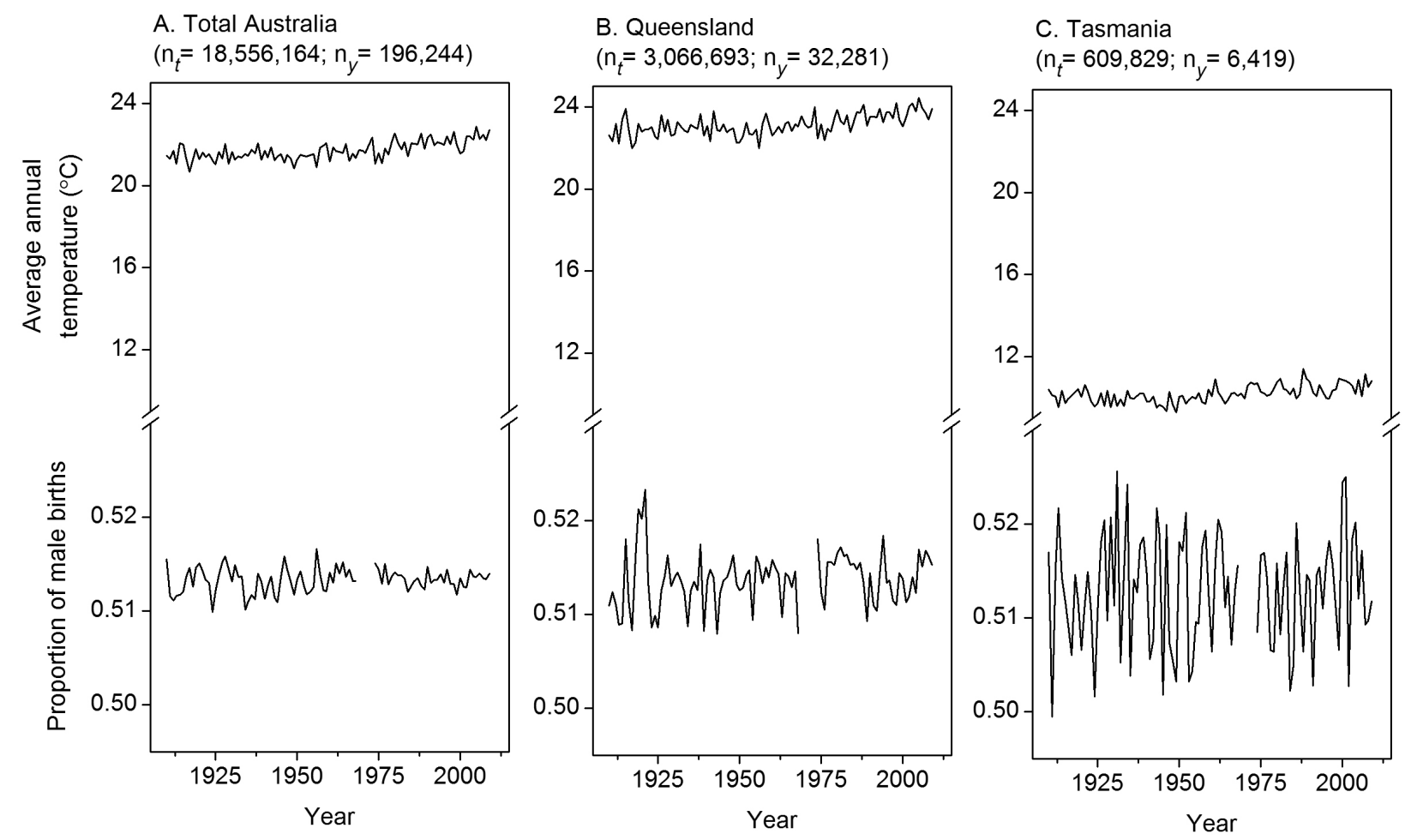